\title{
Secondary stroke prevention among stroke survivors in Riyadh city, Saudi Arabia
}

\section{Risk Knowledge, adherence to stroke discharge medications and preventive strategies}

Shaykhah F. Albusayni, MBBS, Nora M. Abanmi, MBBS, Najla A. Abanemai, MBBS, Roba M. Alharbi, MBBS, Forat A. AlAtiyah, MBBS, Sawsan M. Abdalla, MD, PhD, Awad A. Alharbi, MD.

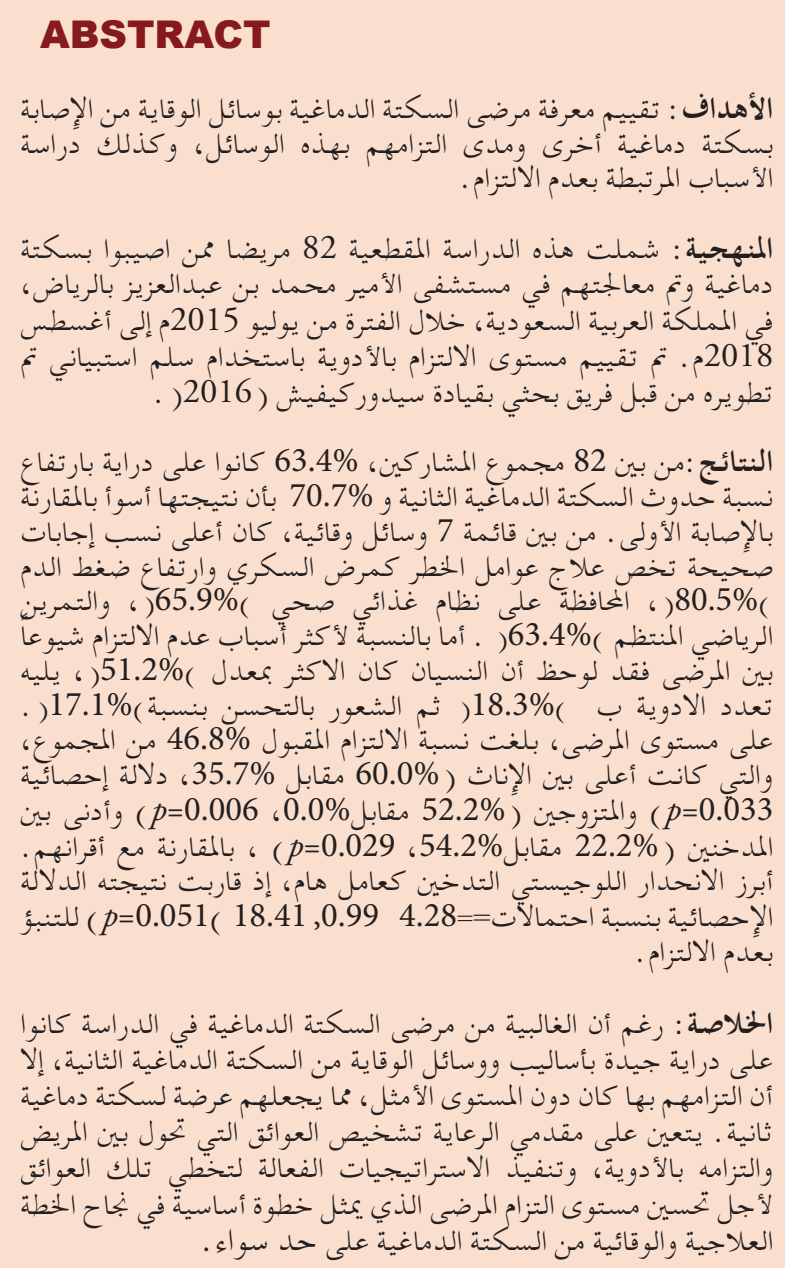

Objectives: To assess knowledge about secondary stroke and adherence to stroke discharge medi-cation and prevention strategies among stroke survivors, and to identify possible causes of poor adherence.

Methods: A cross-sectional study that involved 82 stroke survivors who were treated at Prince Mohammed Bin Abdulaziz Hospital (PMAH) in Riyadh, Saudi Arabia, from July 2015 to August
2018. Patient adherence level (PAL) was assessed using a tool de-veloped by Sidorkiewicz et al (2016).

Results: Of the 82 participants, $63.4 \%$ believed that the risk of secondary stroke is higher and $70.7 \%$ believed it would results in worse outcome, compared to primary stroke. Out of a list of 7 preventive strategies, treating risk factors $(80.5 \%)$, keeping a healthy diet $(65.9 \%)$ and regular exercise $(63.4 \%)$ were the most frequently identified. Forgetfulness $(51.2 \%)$, polypharmacy $(18.3 \%)$ and patientperceived improvement $(17.1 \%)$ were the most frequently reported causes for nonadherence. At the patients' level, PAL was adequate among $46.8 \%$, and was higher among females $(60.0 \%$ versus $35.7 \%$, $p=0.033)$ and married (52.2\% versus $0.0 \%, p=0.006)$ ones, and lower among smokers $(22.2 \%$ versus $54.2 \%, p=0.029)$, compared to their counterparts. No correlation of adherence level with knowledge was observed. Regression showed approximation to statistical significance for smoking $(\mathrm{OR}=4.28$ $[0.99,18.41], p=0.051)$ as a predictor for inadequate adherence.

Conclusion: Stroke survivors have suboptimal adherence to discharge prescriptions and preventive strategies, despite a relatively sound knowledge, which exposes them to high risk of secondary stroke. It is part of the healthcare providers' role to identify eventual barriers to adherence and to implement efficacious strategies to alleviate such barriers and improve patients' adherence.

Neurosciences 2020; Vol. 25 (2): 118-128 doi: 10.17712/nsj.2020.2.20190059

From the College of Medicine (Alhusayni, Abanmi NM, Abanemai NA, Alharbi R, AlAtiyah), from the Department of Public Health \& Community Medicine (Abdalla), Majmaah University, Almajmaah, and from the Department of Neurology (Al Harbi A),King Abdullah Bin Abdulaziz University Hospital, Riyadh, Kingdom of Saudi Arabia

Received 12th July 2019. Accepted 31st December 2019.

Address correspondence and reprint request to: Dr. Shaykhah $F$. Alhusayni, College of Medicine, Majmaah University, Almajmaah, Kingdom of Saudi Arabia. E-mail: shaykhahfahad@gmail.com ORCID ID: https://orcid.org/0000-0003-4020-5548 
$S^{\text {a }}$ troke is an acute neurological deficit that involves a specific area of the central nervous system due to an impairment of the cerebral perfusion or vasculature. This causes ischemia of the affected area, depolarization of cells, and a series of oxidative changes that finally lead to apoptosis and excitotoxicity. ${ }^{1}$ In majority cases $(85 \%)$, stroke is due to a thrombotic or embolic event that reduces the blood flow to the brain (ischemic stroke [IS]), whereas the second more frequent entity, hemorrhagic stroke (HS) is due to intracerebral hemorrhage by rupture of the small cerebral arteries. ${ }^{2}$

Stroke ranks second among the leading causes of mortality worldwide and its epidemiological picture of stroke emphasizes its significant burden on the health. In 2016, about 5.5 million deaths were attributable to stroke, with an approximate equal gender distribution $\left(52.7 \%\right.$ in males). ${ }^{3}$ Stroke is also the second leading cause of disability-adjusted life years (DALYs). ${ }^{4}$ The disease is still prevalent among more than 80 million survivors globally and the absolute numbers of incident cases and deaths are increasing. In Saudi Arabia, several risk factors of stroke, such as hypertension, smoking, and obesity, are still not adequately managed. Furthermore, stroke care is still suboptimal as compared to developed countries, ${ }^{6}$ and there is a lack of robust organizational processes of care and inadequate allocation of resources. ${ }^{6,7}$ This would in turn cause significant consequences in the affected patients.

Stroke survivors are generally at an increased risk for significant morbidity. Of note, after the onset of stroke, patients with hypertension, atrial fibrillation, diabetes, and coronary heart disease are prone to stroke recurrence. ${ }^{8}$ About $11 \%$ of patients might have a recurrent event within one year, $26 \%$ within the next 5 years, and $40 \%$ within 10 years. ${ }^{9}$ Therefore, in addition to the specific medical and rehabilitative interventions, preventing stroke recurrence is an essential element of post-stroke patient care. ${ }^{10}$ Secondary stroke prevention comprises of several approaches, including nutritional interventions, anti-hypertensive measures, anticoagulation, antiplatelet therapy, lipidlowering therapy, and management of intracranial stenosis. ${ }^{11}$ The key to select the best managemental approach is to identify the cause of the event. It has been previously estimated that approximately $80 \%$ of secondary events could be prevented via medical

Disclosure. Authors have no conflict of interests, and the work was not supported or funded by any drug company. and lifestyle interventions. ${ }^{12}$ However, it is imperative to ensure patients' adherence, particularly with the pharmacological therapy. Additionally, barriers to adherence, which may be patient-related or -unrelated, should be explored and alleviated for better efficacy of the preventive strategy.

In essence, compliance to treatment is one of the major challenges to preventing stroke recurrence. Nonadherence, defined as a lack of correspondence with the agreed recommendations by a health professional, ${ }^{13}$ can cause increased morbidity, poor health outcomes, and increased costs to healthcare systems. ${ }^{14}$ Additionally, compliance might be compounded by the factors related to caregivers as important providers of care. However, these factors are primarily dependent on scarce studies. In the Saudi context, only $5 \%$ of patients receive care at specific units for stroke; ${ }^{6}$ the impact of the specific knowledge of patients and caregivers on the outcomes of stroke prevention may be more prominent. Understanding the determinants of poor compliance would help in improving post-stroke care and preventing secondary stroke in Saudi Arabia. In this context, the present study aimed to explore the knowledge of stroke patients and or their caregivers regarding the risk of and preventive strategies against secondary stroke events, and to assess their level of adherence to the prescribed medications and to general preventive rules. Further, the association of adherence with knowledge was analyzed and factors and predictors of nonadherence were explored.

Methods. Design \& Setting. A cross-sectional study was conducted among stroke survivors, who were treated at Prince Mohammed Bin Abdulaziz Hospital (PMAH), Riyadh City, Saudi Arabia, during the past 3-year period.

Riyadh is the capital and most populous city of Saudi Arabia, with an estimated population of 6,506,700 and an area of 380,000 square kilometers. Prince Mohammed Bin Abdulaziz Hospital (PMAH) is a 500-bed hospital that provides secondary and tertiary healthcare services. The range of services PMAH provides makes it one of the largest referral hospitals in the country for diagnosis and treatment of various acute and chronic medical and surgical conditions.

Population and sampling. The total number of patients who were admitted to PMAH, for stroke, during the period from July 2015 to August 2018 was estimated at 156 patients, approximately. A convenience sampling was used to include all survivors among these patients, who accepted to participate either personally or via their caregiver. Participants who were not reachable by telephone and those who were not able to 
understand and or complete the questionnaire were not included.

Data collection. A semi-structured questionnaire was used to collect study data, which originated from 2 sources including patients' medical records and structured telephone interviews of the patients or their respective caregivers. The questionnaire was developed based on literature reviews ${ }^{15-17}$ and comprised 4 sections. The first section consisted of general demographic and clinical data including age, gender, social history, presence of major stroke risk factors (hypertension, diabetes, smoking, etc.), time since stroke, stroke type (ischemic, hemorrhagic, or transient ischemic attack) and number of medications taken per day. The second section assessed participants' knowledge regarding secondary stroke among stroke survivors, including risk level (lower, similar or higher) and outcome severity (worse, similar and better), by reference to primary stroke among general population. Additionally, participants' knowledge about a panel of 7 prevention strategies (treatment of risk factors, healthy diet, regular exercise, etc.) was assessed, along with their eventual sources of knowledge. The third section evaluated patients' adherence to secondary stroke prevention including drugs that were prescribed at primary stroke discharge, among 6 prelisted types including antiplatelet, anticoagulant, antihypertensive, oral hypoglycemic medication, insulin, and lipid lowering agents. Adherence level was measured for each drug individually, by using the self-reported adherence questionnaire developed by Sidorkiewicz et al, 2016. ${ }^{17}$ The questionnaire describes the different medicationtaking behaviors, which enables classifying drug adherence into 6 levels: level 1 "high", level 2 "good", level 3 "moderate", level 4 "poor", level 5 "very poor" and level 6 "drug discontinuation". ${ }^{16}$ Besides, adherence to lifestyle recommendations (healthy diet, smoking cessation, weight control, and regular exercise) was assessed using binary questions (yes or no). The fourth section explored eventual reasons for nonadherence using a panel of 12 most probable reasons such as forgetfulness, concerns about side effects, lack of support, etc., completed by an open item for further non-listed items.

Outcome definition. The primary outcome consisted of the patient adherence level (PAL), which was computed using 2 different methods:

In the first method, PAL was defined as the adherence level for the drug for which the patient was the most non-adherent, i.e. the drug that had the highest score. We obtained a discrete variable ranging from 1 to 6 , with higher values indicating poorer adherence.

In the second method, PAL was calculated as the
Table 1 - Socio demographic and clinical characteristics of patients. $(\mathrm{N}=82)$

\begin{tabular}{|c|c|c|}
\hline Parameter Category & $\mathrm{n}$ & $(\%)$ \\
\hline \multicolumn{3}{|l|}{$\begin{array}{l}\text { Demographic data } \\
\text { Age group (years) }\end{array}$} \\
\hline $\begin{array}{l}31-50 \\
51-50 \\
>60 \text { years old }\end{array}$ & $\begin{array}{l}19 \\
17 \\
46\end{array}$ & $\begin{array}{l}(23.2) \\
(20.7) \\
(56.1)\end{array}$ \\
\hline \multicolumn{3}{|l|}{ Gender } \\
\hline $\begin{array}{l}\text { Male } \\
\text { Female }\end{array}$ & $\begin{array}{l}47 \\
35\end{array}$ & $\begin{array}{l}(57.3) \\
(42.7)\end{array}$ \\
\hline \multicolumn{3}{|l|}{ Marital status } \\
\hline $\begin{array}{l}\text { Single } \\
\text { Married } \\
\text { Divorced or widowed }\end{array}$ & $\begin{array}{l}5 \\
70 \\
7\end{array}$ & $\begin{array}{l}(6.1) \\
(85.4) \\
(8.5)\end{array}$ \\
\hline \multicolumn{3}{|l|}{ Level of education } \\
\hline $\begin{array}{l}\text { Non-educated } \\
\text { Primary } \\
\text { Elementary } \\
\text { High school } \\
\text { University and above } \\
\text { Not answered }\end{array}$ & $\begin{array}{l}25 \\
19 \\
7 \\
12 \\
14 \\
5\end{array}$ & $\begin{array}{l}(30.5) \\
(23.2) \\
(8.5) \\
(14.6) \\
(17.1) \\
(6.1)\end{array}$ \\
\hline \multicolumn{3}{|l|}{$\begin{array}{l}\text { Clinical data } \\
\text { Type of stroke }\end{array}$} \\
\hline $\begin{array}{l}\text { Ischemic stroke } \\
\text { Hemorrhagic stroke } \\
\text { Transient ischemic attack } \\
\text { Do not know }\end{array}$ & $\begin{array}{l}55 \\
4 \\
5 \\
18\end{array}$ & $\begin{array}{l}(67.1) \\
(4.9) \\
(6.1) \\
(22.0)\end{array}$ \\
\hline \multicolumn{3}{|l|}{ Time since stroke } \\
\hline $\begin{array}{l}\leq 1 \text { year } \\
>1 \text { year }\end{array}$ & $\begin{array}{l}52 \\
30\end{array}$ & $\begin{array}{l}(63.4) \\
(36.6)\end{array}$ \\
\hline \multicolumn{3}{|l|}{ Risk factors } \\
\hline $\begin{array}{l}\text { No risk factor } \\
\text { One risk factor } \\
2+\text { risk factors }\end{array}$ & $\begin{array}{l}6 \\
14 \\
62\end{array}$ & $\begin{array}{l}(7.3) \\
(17.1) \\
(75.6)\end{array}$ \\
\hline \multicolumn{3}{|l|}{ Type(s) of risk factor ${ }^{\dagger}$} \\
\hline $\begin{array}{l}\text { Hypertension } \\
\text { Diabetes Mellitus } \\
\text { Hypercholesterolemia } \\
\text { Smoking } \\
\text { Alcohol abuse }\end{array}$ & $\begin{array}{l}64 \\
48 \\
47 \\
18 \\
0\end{array}$ & $\begin{array}{l}(78.0) \\
(58.5) \\
(57.3) \\
(22.0) \\
(0.0)\end{array}$ \\
\hline \multicolumn{3}{|l|}{ No. medications per day } \\
\hline $\begin{array}{l}<5 \\
\geq 5\end{array}$ & $\begin{array}{l}52 \\
30\end{array}$ & $\begin{array}{l}(63.4) \\
(36.6)\end{array}$ \\
\hline \multicolumn{3}{|l|}{ Tobacco use before stroke } \\
\hline $\begin{array}{l}\text { Yes } \\
\text { No }\end{array}$ & $\begin{array}{l}18 \\
64\end{array}$ & $\begin{array}{l}(22.0) \\
(78.0)\end{array}$ \\
\hline \multicolumn{3}{|l|}{$\begin{array}{l}\text { Lifestyle after stroke } \\
\text { Quite smokings }\end{array}$} \\
\hline $\begin{array}{l}\text { Yes } \\
\text { No }\end{array}$ & $\begin{array}{l}5 \\
13\end{array}$ & $\begin{array}{l}(27.8) \\
(72.2)\end{array}$ \\
\hline \multicolumn{3}{|l|}{ Regular exercise } \\
\hline $\begin{array}{l}\text { Yes } \\
\text { No }\end{array}$ & $\begin{array}{l}26 \\
56\end{array}$ & $\begin{array}{l}(31.7) \\
(68.3)\end{array}$ \\
\hline \multicolumn{3}{|l|}{ Healthy diet } \\
\hline $\begin{array}{l}\text { Yes } \\
\text { No }\end{array}$ & $\begin{array}{l}58 \\
24\end{array}$ & $\begin{array}{l}(70.7) \\
(29.3)\end{array}$ \\
\hline \multicolumn{3}{|l|}{ Weight control } \\
\hline $\begin{array}{l}\text { Yes } \\
\text { No }\end{array}$ & $\begin{array}{l}56 \\
26\end{array}$ & $\begin{array}{l}(68.3) \\
(31.7)\end{array}$ \\
\hline
\end{tabular}


Table 2 - Knowledge of patients toward secondary stroke.

\begin{tabular}{lc}
\hline Item / answering option & N (\%) \\
\hline Compared to the general population, patients with previous strokes have a_risk of stroke recurrence & \\
Lower & $4(04.9)$ \\
Similar & $26(31.7)$ \\
${ }^{*}$ Higher & $52(63.4)$ \\
Compared to previous stroke, the outcome of the second stroke will be _ & \\
*Worse & $58(70.7 \%)$ \\
Same & $15(18.3 \%)$ \\
Better & $9(11.0 \%)$ \\
†Strategies that help prevent a secondary stroke & \\
Risk factors treatment (Diabetes, Hypertension, etc.) & $66(80.5 \%)$ \\
Healthy diet that is low in fat and salt & $54(65.9 \%)$ \\
Regular exercise & $52(63.4 \%)$ \\
Usage of antiplatelet therapy and anticoagulants & $47(57.3 \%)$ \\
Quit smoking & $41(50.0 \%)$ \\
Weight control & $40(48.8 \%)$ \\
Reduction and avoidance of alcohol & $20(24.4 \%)$ \\
Sources of information $\dagger$ & \\
Doctors and hospital teams & $51(62.2 \%)$ \\
Family and friends & $29(35.4 \%)$ \\
Social media and internet & $18(22.0 \%)$ \\
Mass media & $5(6.1 \%)$ \\
Other & $9(11.0)$ \\
\hline
\end{tabular}

mean drug adherence level using the following formula: $\mathrm{PAL}=\left(\sum\right.$ drug adherence levels $) /$ (number of drugs prescribed at stroke discharge)

We obtained a continuous variable ranging from 1 to 6 , with higher values indicating poorer adherence.

Statistical methods. Data was entered and analyzed using the Statistical Package for Social Sciences version 21.0 for Windows (SPSS Inc., Chicago, IL, USA). Descriptive statistics were carried out to present sociodemographic and clinical data, patterns of answers to the different questionnaire sections, and the drug and patient adherence levels. Findings were summarized as numbers and percentages for categorical variables and mean (SD) values for continuous variables. The discrete PAL variable was transformed into a binary variable, by dichotomizing adherence level into adequate (high or good [score $=1,2]$ ) versus inadequate (moderate or poorer [score $\geq 3]$ ) adherence. The percentage of patients with adequate adherence was compared across the different factor categories using chi square or Fisher's exact test, as appropriate. Further, the continuous PAL variable was compared between the factors' categories using nonparametric tests, including Mann-Whitney U and Kruskal-Wallis tests for factors with binomial and multinomial variables, respectively. Multivariate binary regression was carried out to analyze the independent factors of nonadherence, including factors that showed significance in either 2 previous analyses; results were presented as odd ratio (OR) with 95\% confidence interval $(95 \% \mathrm{CI})$. For all the test, statistical significance was assumed for a $p$-value $<0.05$.

Ethical considerations. Informed consent was obtained verbally from all participants, who were invited

Table 3 - Drug and patient adherence levels ( $N=77)$.

\begin{tabular}{lccc}
\hline Outcome & \multicolumn{3}{c}{ Adherence level, N (\%) } \\
\cline { 3 - 4 } & $\mathrm{N}$ & $\begin{array}{c}\text { Adequate } \\
(\mathbf{1 - 2})\end{array}$ & $\begin{array}{c}\text { Inadequate } \\
(3-6)\end{array}$ \\
\hline Drug adherence level & & & \\
Antiplatelet & 61 & $41(67.2)$ & $20(32.8)$ \\
Anticoagulant & 40 & $21(52.5)$ & $19(47.5)$ \\
Anti-hypersensitive & 62 & $52(83.9)$ & $10(16.1)$ \\
Oral hypoglycemic & 36 & $24(66.7)$ & $12(33.3)$ \\
Insulin & 23 & $23(100.0)$ & $0(0.0)$ \\
Lipid-lowering agent & 46 & $37(80.4)$ & $9(19.6)$ \\
Patient adherence level & 77 & $36(46.8)$ & $41(53.2)$ \\
\hline
\end{tabular}


Table 4 - Factors association with patient adherence level.

\begin{tabular}{|c|c|c|c|c|}
\hline Factors Category & Adequate n (\%) & $P$-value ${ }^{1}$ & Mean Patient adherence level & $P$-value ${ }^{2}$ \\
\hline \multicolumn{5}{|l|}{$\begin{array}{l}\text { Demographic factors } \\
\text { Age group (years) }\end{array}$} \\
\hline $\begin{array}{l}31-50 \\
51-50 \\
>60\end{array}$ & $\begin{array}{l}9(50.0) \\
7(43.8) \\
20(46.5)\end{array}$ & .935 & $\begin{array}{l}2.16 \\
2.44 \\
2.11\end{array}$ & .941 \\
\hline $\begin{array}{l}\text { Gender } \\
\text { Male } \\
\text { Female }\end{array}$ & $\begin{array}{l}15(35.7) \\
21(60.0)\end{array}$ & $.033^{*}$ & $\begin{array}{l}2.62 \\
1.67\end{array}$ & $.003^{*}$ \\
\hline $\begin{array}{l}\text { Marital status } \\
\text { Single or separated } \\
\text { Married }\end{array}$ & $\begin{array}{c}0(0.0) \\
36(52.2)\end{array}$ & $.006^{*}$ & $\begin{array}{l}3.04 \\
2.09\end{array}$ & $.025^{*}$ \\
\hline $\begin{array}{l}\text { Level of education } \\
\text { Low (up to elementary) } \\
\text { High (high school+) }\end{array}$ & $\begin{array}{l}27(54.0) \\
8(32.0)\end{array}$ & .072 & $\begin{array}{l}1.91 \\
2.80\end{array}$ & $.014^{*}$ \\
\hline $\begin{array}{l}\text { Clinical data } \\
\text { Type of stroke }\end{array}$ & & & & \\
\hline $\begin{array}{l}\text { Ischemic } \\
\text { Other }\end{array}$ & $\begin{array}{l}21(42.0) \\
15(55.6)\end{array}$ & .255 & $\begin{array}{l}2.33 \\
1.94\end{array}$ & .291 \\
\hline Time since stroke & & & & \\
\hline $\begin{array}{l}\leq 1 \text { year } \\
>1 \text { year }\end{array}$ & $\begin{array}{l}26(53.1) \\
10(35.7)\end{array}$ & .142 & $\begin{array}{l}2.04 \\
2.45\end{array}$ & .166 \\
\hline $\begin{array}{l}\text { No. medications per day } \\
<5 \\
\geq 5\end{array}$ & $\begin{array}{l}24(51.1) \\
12(40.0)\end{array}$ & .343 & $\begin{array}{l}2.28 \\
2.06\end{array}$ & .788 \\
\hline $\begin{array}{l}\text { Tobacco use } \\
\text { Yes } \\
\text { No }\end{array}$ & $\begin{array}{c}4(22.2) \\
32(54.2)\end{array}$ & $.029^{*}$ & $\begin{array}{l}2.82 \\
2.00\end{array}$ & $.011^{*}$ \\
\hline $\begin{array}{l}\text { Lifestyle } \\
\text { Regular exercise }\end{array}$ & & & & \\
\hline $\begin{array}{l}\text { Yes } \\
\text { No }\end{array}$ & $\begin{array}{l}15(60.0) \\
21(40.4)\end{array}$ & .106 & $\begin{array}{l}1.93 \\
2.23\end{array}$ & .151 \\
\hline Healthy diet & & & & \\
\hline $\begin{array}{l}\text { Yes } \\
\text { No }\end{array}$ & $\begin{array}{l}27(48.2) \\
9(42.9)\end{array}$ & .675 & $\begin{array}{l}2.07 \\
2.53\end{array}$ & .285 \\
\hline $\begin{array}{l}\text { Weight control } \\
\text { Yes } \\
\text { No }\end{array}$ & $\begin{array}{l}27(50.0) \\
9(39.1)\end{array}$ & .382 & $\begin{array}{l}2.07 \\
2.48\end{array}$ & .337 \\
\hline $\begin{array}{l}\text { Knowledge level } \\
\text { Risk of recurrence }\end{array}$ & & & & \\
\hline $\begin{array}{l}\text { Incorrect } \\
\text { Correct }\end{array}$ & $\begin{array}{l}15(50.0) \\
21(44.7)\end{array}$ & .648 & $\begin{array}{l}1.95 \\
2.35\end{array}$ & .312 \\
\hline $\begin{array}{l}\text { Severity of second stroke } \\
\text { Incorrect } \\
\text { Correct }\end{array}$ & $\begin{array}{l}11(45.8) \\
25(47.2)\end{array}$ & .913 & $\begin{array}{l}2.02 \\
2.27\end{array}$ & .755 \\
\hline $\begin{array}{l}\text { Prevention strategies ident } \\
<3 \\
3+\end{array}$ & $\begin{array}{c}8(38.1) \\
28(50.0)\end{array}$ & .351 & $\begin{array}{l}2.26 \\
2.17\end{array}$ & .614 \\
\hline $\begin{array}{l}\text { Source of knowledge } \\
\text { Doctor } \\
\text { No } \\
\text { Yes }\end{array}$ & $\begin{array}{l}11(40.7) \\
25(50.0)\end{array}$ & .437 & $\begin{array}{l}2.42 \\
2.07\end{array}$ & .413 \\
\hline $\begin{array}{l}\text { Family \& Friends } \\
\text { No } \\
\text { Yes }\end{array}$ & $\begin{array}{l}22(45.8) \\
14(48.3)\end{array}$ & .835 & $\begin{array}{l}2.16 \\
2.25\end{array}$ & .925 \\
\hline $\begin{array}{l}\text { Social media } \\
\text { No } \\
\text { Yes }\end{array}$ & $\begin{array}{l}25(42.4) \\
11(61.1)\end{array}$ & .163 & $\begin{array}{l}2.23 \\
2.06\end{array}$ & .294 \\
\hline
\end{tabular}




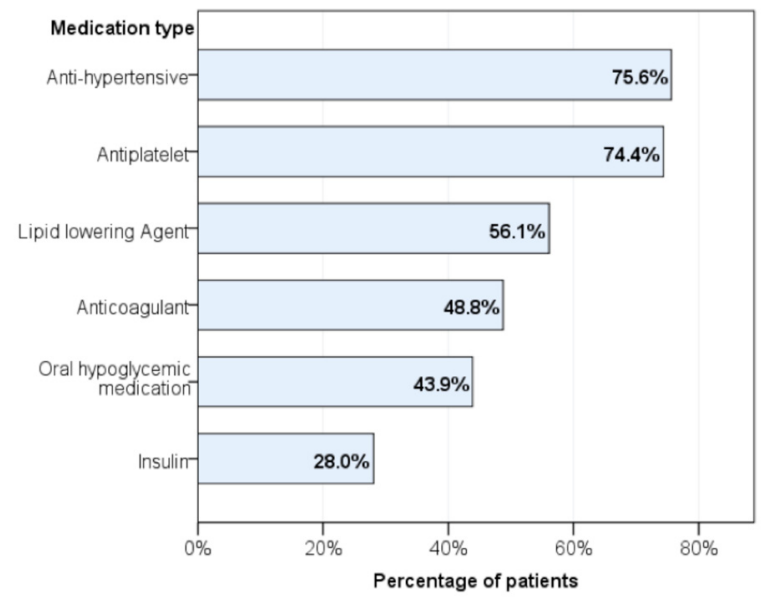

Figure 1 - Discharge prescribing pattern by medication type

to participate with their complete volunteering and without any suggestive emotional or mental pressure to participate. Respect and dignity were maintained during the interview, along with utmost confidentiality throughout and the entire research process. The study protocol was reviewed and approved by the ethical committee of PMAH.

Results. Socio demographic characteristics of patients. Of 156 patients who fulfilled eligibility criteria, 82 patients completed the question-naire (response rate $=52.6 \%$ ), while the remainders included those who refused to participate $(13,8.3 \%)$, were unresponsive $(55,35.3 \%)$ or deceased $(6,3.8 \%)$. Of the 82 participants, majority were elderly (56.1\%), males $(57.3 \%)$ and married (85.4\%). Type and time of stroke showed majority of ischemic stroke (67.1\%) that occurred recently (63.4\%). Hypertension was the most prevalent risk factor $(78.0 \%)$, followed by diabetes (58.5\%) and hypercholesterolemia (57.3\%), and $36.6 \%$ declared having 5 or more medications per day (Table 1). According to participants, discharge prescriptions included antihypertensive treatment (75.6\%), antiplatelet (74.4\%), and lipid lowering agents $(56.1 \%)$, while anticoagulants were prescribed for only $48.8 \%$ of the patients (Figure 1). Subsequent to stroke episode, lifestyle was marked by low percentage of regular exercise $(31.7 \%)$, whereas majority declared complying with a healthy diet $(70.7 \%)$ and controlling their weight $(68.3 \%)$. Further, $72.2 \%$ of smokers continued smoking after their stroke episode (Table 1).

Knowledge of patients regarding secondary strokes. Majority of the patients believed that history of stroke

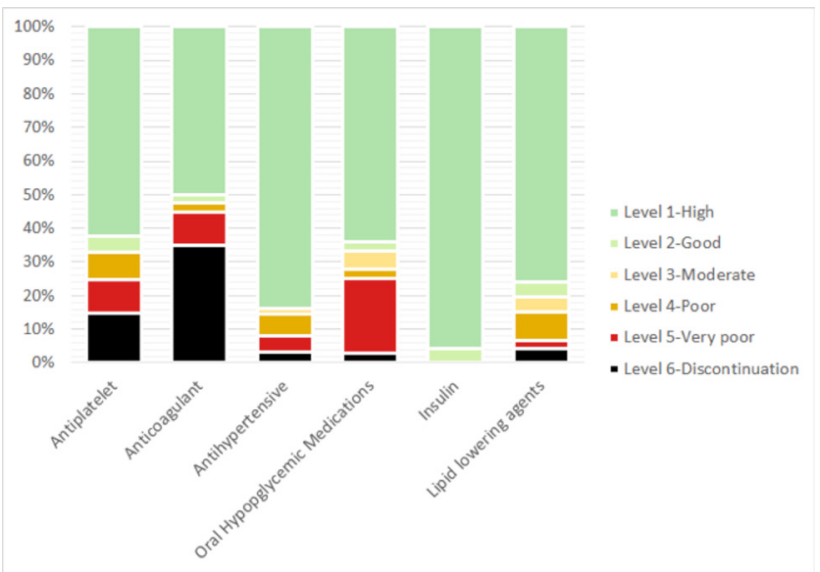

Figure 2 - Drug adherence level by different medication classes. Bar correspond to medication classes, and colored segments correspond to the percentage of patients with the respective drug adherence level, within the given medication class.

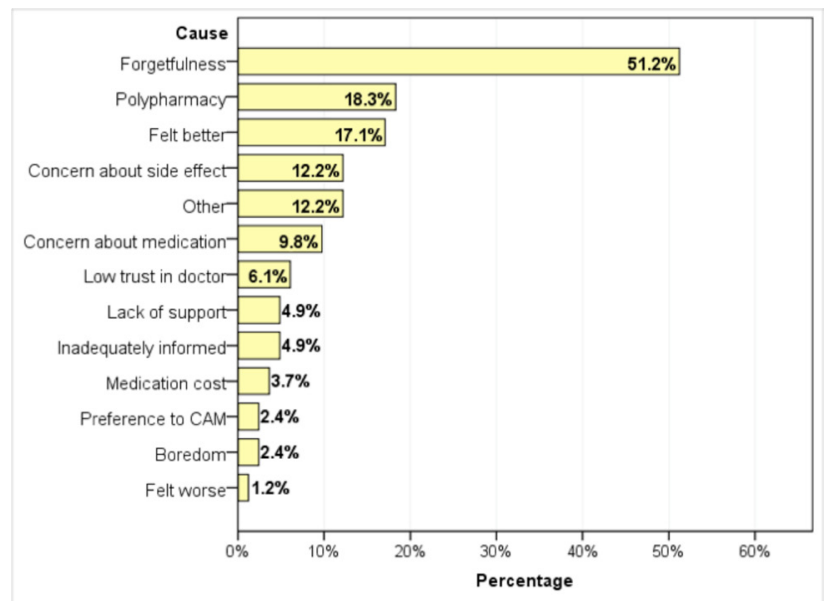

Figure 3 - Causes of non-adherence to post-stroke medications. Bars represent the percentage of patients who reported the given cause as a plausible motivation for nonadherence. CAM - Complementary and alternative medicine

exposes to higher risk of having a secondary episode $(63.4 \%)$, while others believed the risk of recurrence was either similar to $(35.4 \%)$ or lower $(4.9 \%)$ than primary stroke among general population. Majority correctly stated that an eventual secondary stroke would results in worse outcome than the primary one $(70.7 \%)$, while the remainders believed the outcomes would be similar $(18.3 \%)$ or better $(11.0 \%)$. Treating risk factors such as diabetes, hypertension, etc. (80.5\%), keeping a healthy diet $(65.9 \%)$ and regular exercise (63.4\%) were the 3 most frequently identified strategies to prevent secondary stroke. On the other hand, majority failed to identify weight control and reduction 
of avoidance of alcohol as preventive strategies. Doctors and hospital teams were the most common sources of survivors' information (62.2\%) regarding secondary strokes, followed by family and friends (35.4\%); while only $22 \%$ of the patients referred to social media and internet sources and $6.1 \%$ to mass media (Table 2).

Causes of non-adherence. The most frequently reported cause for non-adherence was forgetfulness (51.2\%), followed by polypharmacy (18.3\%) and patient-perceived improvement (17.1\%) (Figure 3).

Level of adherence. Of the 82 participants, 5 had none of the 6 explored medications. Consequently, the following analysis will concern the remaining 77 ones. At the medication level, all 23 patients on insulin had adequate (high or good) drug adherence level (100\%). Other medications showed relatively high drug adherence level for antihypertensive (83.9\%), followed by LLD $(80.4 \%)$; whereas adherence to antiplatelet and anticoagulants was $67.2 \%$ and $52.5 \%$, respectively; and the 2 medications had the highest percentage of discontinuation (Table 3, Figure 2). At the patient level, adherence was high $(35,45.5 \%)$, good $(1,1.3 \%)$, moderate $(2,2.6 \%)$, poor $(7,8.5 \%)$, and very poor $(11$, $13.4 \%)$; while discontinuation was observed among $21(25.6 \%)$ of the 77 patients (results not presented). Consequently, PAL was adequate among $46.8 \%$ of the patients (Table 3).

Factors associated with adherence. Adherence was higher among females, who had higher percentage of adequacy $(60.0 \%$ versus $35.7 \%, p=0.033)$ and more favorable mean adherence score (1.67 versus 2.62, $p=0.003)$ compared to males. Likewise, adherence rate was higher among married participants $(52.2 \%$ versus $0.0 \%, p=0.006)$ with more favorable mean adherence score (2.09 versus 3.04, $p=0.025$ ), compared to their counterparts. Paradoxically, lower educational level (up to elementary school) was associated with better adherence including adequacy rate $(54.0 \%$ versus $32.0 \%$ ) and mean adherence score (1.91 versus 2.80), compared to counterparts, respectively; however, the difference was only significant for mean adherence $(p=0.014)$. It is worth noting that participants with recent stroke ( $\leq 1$ year) had higher adequacy rate $(53.1 \%)$ compared to their counter-parts $(35.7 \%)$, however, the result was not statistically significant $(p=0.142)$. On the other hand, tobacco users had lower adherence both using adequacy rate $(22.2 \%$ versus $54.2 \%, p=0.029)$ and mean adherence score ( 2.00 versus $2.82, p=0.011$ ), compared to nonsmokers, respectively. No significant association was found between adherence level and knowledge level, source of knowledge or lifestyle factors (Table 4).
Predictors of inadequate adherence. A multivariate binary regression model was carried out to analyze gender, education level and smoking status as independent factors of inadequate adherence, the dependent variable. Results showed

higher risk of non-adherence among active smokers $(\mathrm{OR}=4.28 \quad[95 \% \quad \mathrm{CI}=0.99,18.41])$ with nearly significant level $(p=0.051)$; while male (OR=1.74 [95\% $\mathrm{CI}=0.60,5.03], p=0.309)$ and high educational level (2.14 [0.72, 6.31], $p=0.170)$ where out of range of statistical significance (Results are not presented).

Discussion. Summary of findings. The present study focused on the post stroke phase of 82 stroke survivors, by exploring their level of knowledge and awareness about secondary stroke prevention as well as their level of adherence to post stroke medication and preventive strategies. It also investigated barriers to adherence and analyzed sociodemographic and clinical factors and predictors of nonadherence, in addition to the association of knowledge with adherence level. Findings showed relatively low knowledge regarding the risk and severity of secondary stroke, with inconsistent awareness about the different preventive strategies; along with inadequate adherence to prescribed medications among more than half of the concerned patients. Specific adherence varied by type of medication, and overall adherence was better among females, married and nonsmokers, while it was not associated with knowledge level not predicted by any of the explored factors. Forgetfulness, polypharmacy and perceived improvement: the 3 major barriers to adherence.

Knowledge and awareness about secondary stroke and preventive strategies. Intuitively, awareness and knowledge of stroke patients has a strong implication in reducing the risk of recurrent events. A considerable proportion of patients in the present study correctly perceived the increased risk of having a recurrent stroke after an index event (63.4\%), and that such event would have worse outcomes than the primary one $(70.7 \%)$. Previous studies indicated the importance of considering secondary preventive approaches in older adults with a history of stroke, particularly IS, since experiencing an initial event would be a strong predictor of further events. ${ }^{18-21}$ Besides, recurrent stroke can cause significant morbidity, as indicated by stroke-related hospitalization or admission to complex continuing care, disability, cognitive decline, and dementia and increases the risk of mortality up to 5 years after stroke. ${ }^{21,22}$

However, the perceived risks of subsequent events as well as the worse outcomes of secondary stroke were rarely investigated previously among stroke survivors. Only $23 \%$ and $40 \%$ of stroke patients identified the 
increased likelihood of having a secondary event in Scotland ${ }^{23}$ and Namibia, ${ }^{15}$ respectively. Instead, most of the conducted cross-sectional studies were concerned with the assessment of knowledge regarding risk factors of stroke in general. A systematic review of 18 studies (8147 patients) showed limited knowledge and low awareness levels about stroke risk factors, and about $22-33 \%$ only were able to describe at least three risk factors. ${ }^{24}$ Simultaneously, stroke survivors could not recognize stroke symptoms despite their previous experience, and had low awareness about their risk for a secondary stroke. Such unawareness may decrease patients' engagement in the preventive measures against secondary stroke. Contrasting with our findings, studies employing surveys with open-ended questions indicated low rates of knowledge. ${ }^{24,25}$ Nonetheless, the use of closed-ended questions in the present study might have overestimated the real knowledge levels in some domains.

Doctors and other healthcare providers were the major source of information about stroke and its preventive strategies (in $62.2 \%$ of patients), in the present study. Healthcare professional have also been the main sources of knowledge in more than $75 \%$ of patients in a study conducted in Thailand. ${ }^{25}$ However, knowledge about stroke did not reach satisfactory levels in our study and other studies. This may indicate that information or the method of providing information may be inadequate to raise knowledge to the adequate levels. The methods of communication and/or barriers of perception may account for these observations. In Saudi Arabia, there is a significant cultural diversity of healthcare providers, which could be a major determinant of communication. Hence, the process of sharing useful information and promoting behavioral and lifestyle changes among stroke patients may be impaired, which would be reflected in low compliance to such changes and inadequate adherence levels to medication-based preventive strategies.

Adherence to post stroke medications and other preventive strategies. In the present analysis, several factors were associated with adherence. Females were significantly more adherent to treatment than males, and this was also evident in other studies. ${ }^{26,27}$ This might emerge from their higher knowledge levels regarding the risk factors of stroke and cardiovascular diseases in general, which have been shown in earlier local and international investigations. ${ }^{28-30}$ Females, who usually hold the caring role, seem to be more knowledgeable about treatment, and they have an increased interest in gaining knowledge from different sources, a matter which supports their compliance with preventive strategies. Additionally, being married was another factor significantly associated with compliance. Other studies reported the significant impact of the marital status on adherence to oral anticoagulant medications to reduce the risk of recurrent stroke. ${ }^{31,32}$ Caregiver support is an important element in such circumstances, where the patient may be regularly reminded by his/her partner. Conversely, living alone and the lack of family support have been associated with lower compliance in several investigations. ${ }^{26,33}$

Surprisingly, lower educational level was associated with improved adherence among in the present study. Other studies showed contrasting outcomes, such as in Nigeria, where stroke survivors with a tertiary educational level were 48 time more likely to be knowledgeable about stroke and more compliant to treatment than those with lower education. ${ }^{34}$ This was in agreement with other large cohort-sized surveys relying on open-ended questions in Norway and China. ${ }^{35,36}$ However, Saengsuwan et al..$^{25}$ failed to reveal a significant impact of education on stroke knowledge and adherence to post-stroke therapies, possibly due to the small sample size (140 patients). The association between higher adherence and low educational levels in our study may be related to the increased trust in doctors' advice by low-educated patients, which has been consistently reported in patients with hypercholesterolemia. ${ }^{37,38}$

Other factors associated with improved adherence were repeatedly reported in the literature; however, these factors were not significant in our study. For example, there is an evidence indicating that elderly patients are generally more compliant, while younger stroke patients often forget some doses. ${ }^{27,39}$ Furthermore, several studies showed an inverse relationship between time since stroke and compliance, and this was supported by providing a severe medical care to manage chronic stroke patients. ${ }^{26,27,40}$ Although results from our study suggest higher adherence rates $(53.1 \%$ versus $35.7 \%)$ among patients with a recent episode ( $\leq 1$ year) as compared to those with a former one ( $>1$ year), respectively, this difference did not reach statistical significance. It is worth noting that failure to demonstrate the significant association of adherence with these factors, in our study, is probably due to the small sample size inducing significant type II error.

Barriers to adherence. On the other hand, we evidenced a number of barriers to adherence. Nonadherence is classified into intentional (patients' decision to stop treatment or take it in a different way than prescribed) or unintentional (due to forgetting or physical disability). ${ }^{14}$ Forgetfulness was the most frequent barrier in the present study. Jamison et al..$^{41}$ and Chamberset $\mathrm{al}^{42}$ have also emphasized such a problem, 
which may be attributed to cognitive impairments implied in stroke patients. Increased number of coprescribed medications (polypharmacy) and perceived improvements were other significant factors of reduced adherence. ${ }^{43}$ Specific medication management strategies can help overcome these barriers. These include the use of ergonomic storage devices, such as medication wallets and pillboxes. Moreover, it is possible to create distinct daily activities or routines, which could be linked to taking medications or placing the medication in a cue location that make it easier to routinely receive the medication..$^{41}$ Besides, caregivers could be targeted by suitable educational programs to remind patients and to ensure their adherence.

Smoking: a potentially strong predictor of nonadherence. Finally, smoking was a notable factor of adherence and could represent the major predictor of nonadherence in our analysis, by setting the statistical significance to a higher level (e.g. $p<0.06)$. Comparably, cigarette smokers were less persistent to their therapies at one year after stroke in European studies. ${ }^{44,45}$ Therefore, smokers should receive more intensified educational interventions regarding the risks of nonadherence and its relation with secondary stroke.

Education and life after stroke. Based on the aforementioned findings, structured and systematic education appears to be imperative among stroke survivors to enhance their protective behaviors and reduce the risk of recurrence. It should be emphasized that education does not stop at providing the useful information to improve knowledge, but should involve further interventions with broader aims. Inefficacy of knowledge alone may be supported by the lack of association between levels of adherence and knowledge about secondary stroke and preventive strategies in our study. Therefore, education should involve effective and practical actions that improve patient's and or caregiver's proficiency in the management of post stroke care issues including comorbidities, other risk factors, and lifestyle changes. Ovbiagele et al. ${ }^{46}$ have implemented a specialized in-hospital program comprising of 8 measures to ensure adherence, including 4 medication-related (initiating a statin, an antithrombotic, a thiazide diuretic, and an angiotensinconverting enzyme inhibitor) and 4 behavioral-targeting measures (improving stroke awareness diet and exercise counselling and smoking cessation interventions). Ultimately, this led to a significant improvement in the adherence rate and enhanced knowledge about stroke symptomatology and risk factors. Besides, a sustained engagement is warranted on both patient's and care providers' sides, along with a proac-tive relationship to ensure the most favorable outcomes and the best quality of life after stroke.

Limitations. The major limitation for this study is the small sample size, probably inducing significant type II error, which hindered the significance of inferential analysis notably the predictors of nonadherence and limits the generalizability of the results. The other significant limitation is the use of a subjective tool to evaluate patients' adherence, which is subject to both recall bias and response bias, which may result in inaccurate and or obliging answers thereby overestimating adherence. Further, the study failed to probe into the level of patient's autonomy and eventual caregiver's factor, which may have impacted adherence. Other factors were not explored, such as the effects of patients' beliefs about medication and treatment and the psychological determinants of adherence (depression, anxiety, etc.). In addition, causes of treatment discontinuation were not explored, as this may be related to physician's recommendation. Finally, the exclusive dependence on close-ended questions may have overestimated the levels of knowledge and consequently its association with adherence.

Conclusion. Knowledge about the risk and severity of recurrent stroke was relatively adequate among stroke survivors in the present study; this was predominantly acquired from healthcare professionals. Concurrently, patients had low awareness about the adequate preventive lifestyle and medication-based strategies, and more than half of them showed inadequate adherence to the prescribed medications. On the other hand, adherence to discharge prescriptions was low, indicating a gap between knowledge and adherence that should be explored and tackled. The facilitators of adherence included the female gender, being married, and a low educational level, whereas the smoking constituted a major factor of nonadherence.

Stroke survivors and their caregivers should be educated not only about knowledge of the risk factors of recurrence, but also the effective self-management of all the health and care issues. The use of reminders and assistive devices should be encouraged to tackle forgetfulness, the major cause of nonadherence. Targeted programs should include healthcare professionals, patients, and caregivers. Doctor orienting programs could be tailored to enhance their capacity to educate patients, considering the cultural diversity of doctors in Saudi Arabia, since they are the major sources of information to patients. The education and 
management strategies of stroke survivors should enable raising the patients' and care providers' expectations and promoting a paradigm shift from "life after stroke" to "quality of life after stroke".

Acknowledgement. We would like to express our gratitude to the medical students Ammar A. Hakami, Renad O. AlHogail, Almaali M. Alrakha, Nujoud H. al-moqati, Abdulrahman H. Darbashi, Salma E. Algargoosh, Njoud A. Osaysi and Halimah A. Qasem. All of these students have been very helpful and participated in the data collection for this research. We would also like to extend our sincere gratitude to Dr. Waqas Sami for his help in reviewing the methodology and data sheets.

\section{References}

1. Radak D, Katsiki N, Resanovic I, Jovanovic A, SudarMilovanovic E, Zafiro-vic S, et al. Apoptosis and Acute Brain Ischemia in Ischemic Stroke. Curr Vasc Pharmacol 2017; 15: 115-122.

2. Writing Group Members, Mozaffarian D, Benjamin EJ, Go AS, Arnett DK, Blaha MJ, et al. Heart Disease and Stroke Statistics2016 Update: A Report From the American Heart Association. Circulation 2016; 133: e38-e360.

3. GBD Stroke Collaborators. Global, regional, and national burden of stroke, 1990-2016: a systematic analysis for the Global Burden of Disease Study 2016. Lancet Neurol 2019; 18 : 439-458.

4. Gorelick PB. The global burden of stroke: persistent and disabling. Lancet Neurol 2019; 18: 417-418.

5. Almekhlafi MA. Trends in one-year mortality for stroke in a tertiary academic center in Saudi Arabia: a 5-year retrospective analysis. Ann Saudi Med 2016; 36: 197-202.

6. Alanazy MH, Barakeh RB, Asiri A, Edrees MF, Abuzinadah AR, Aljafen BN, et al. Practice Patterns and Barriers for Intravenous Thrombolysis: A Survey of Neurologists in Saudi Arabia. Neurol Res Int 2018; 2018: 1695014-.

7. Al-Senani F, Al-Johani M, Salawati M, ElSheikh S, AlQahtani M, Muthana J, et al. A national economic and clinical model for ischemic stroke care devel-opment in Saudi Arabia: A call for change. Int J Stroke 2019; 14: 835-842.

8. Zheng S, Yao B. Impact of risk factors for recurrence after the first ischemic stroke in adults: A systematic review and metaanalysis. J Clin Neurosci 2019; 60: 24-30.

9. Mohan KM, Wolfe CDA, Rudd AG, Heuschmann PU, Kolominsky-Rabas PL, Grieve AP. Risk and cumulative risk of stroke recurrence: a systematic review and meta-analysis. Stroke 2011; 42: 1489-1494.

10. Krishnan S, Pappadis MR, Weller SC, Stearnes M, Kumar A, Ottenbacher KJ, et al. Needs of Stroke Survivors as Perceived by Their Caregivers: A Scoping Review. Am J Phys Med Rehabil 2017; 96: 487-505.

11. Spence JD. Recent advances in preventing stroke recurrence. F1000Res 2017; 6: 1017.

12. Hackam DG, Spence JD. Combining multiple approaches for the secondary prevention of vascular events after stroke: a quantitative modeling study. Stroke 2007; 38: 1881-1885.

13. Lehane E, McCarthy G. Medication non-adherence--exploring the conceptual mire. Int J Nurs Pract 2009; 15: 25-31.
14. Chapman B, Bogle V. Adherence to medication and selfmanagement in stroke patients. Br J Nurs 2014; 23: 158-166.

15. Peter J, Justus AH. Knowledge and Practices of Stroke Survivors Regarding Secondary Stroke Prevention, Khomas Region, Namibia. Journal of Medical Biomedical and Applied Sciences 2016; 3.

16. Sappok T, Faulstich A, Stuckert E, Kruck H, Marx P, Koennecke HC. Com-pliance with secondary prevention of ischemic stroke: a prospective evalua-tion. Stroke 2001; 32: 1884-1889.

17. Sidorkiewicz S, Tran VT, Cousyn C, Perrodeau E, Ravaud P. Development and validation of an instrument to assess treatment adherence for each indi-vidual drug taken by a patient. BMJ Open 2016; 6: e010510.

18. Coull AJ, Lovett JK, Rothwell PM, Oxford Vascular S. Population based study of early risk of stroke after transient ischaemic attack or minor stroke: implications for public education and organisation of services. BMJ 2004; 328: 326.

19. Clark TG, Murphy MFG, Rothwell PM. Long term risks of stroke, myocardial infarction, and vascular death in "low risk" patients with a non-recent transient ischaemic attack. J Neurol Neurosurg Psychiatry 2003; 74: 577-580.

20. van Wijk I, Kappelle LJ, van Gijn J, Koudstaal PJ, Franke CL, Vermeulen M, et al. Long-term survival and vascular event risk after transient ischaemic at-tack or minor ischaemic stroke: a cohort study. Lancet 2005; 365: 2098-2104.

21. Edwards JD, Kapral MK, Fang J, Swartz RH. Long-term morbidity and mor-tality in patients without early complications after stroke or transient ischemic attack. CMAJ 2017;189: E954-E61.

22. Hardie K, Hankey GJ, Jamrozik K, Broadhurst RJ, Anderson C. Ten-year risk of first recurrent stroke and disability after first-ever stroke in the Perth Com-munity Stroke Study. Stroke 2004; 35: 731-735.

23. Wellwood I, Dennis MS, Warlow CP. Perceptions and knowledge of stroke among surviving patients with stroke and their carers. Age Ageing 1994; 23: 293-298.

24. Ellis C, Barley J, Grubaugh A. Poststroke knowledge and symptom aware-ness: a global issue for secondary stroke prevention. Cerebrovasc Dis 2013; 35: 572-581.

25. Saengsuwan J, Suangpho P, Tiamkao S. Knowledge of Stroke Risk Factors and Warning Signs in Patients with Recurrent Stroke or Recurrent Transient Ischaemic Attack in Thailand. Neurol Res Int 2017; 2017: 8215726.

26. Sjölander M, Eriksson M, Glader EL. The association between patients' be-liefs about medicines and adherence to drug treatment after stroke: a cross-sectional questionnaire survey. BMJ Open 2013; 3: e003551.

27. Cheiloudaki E, Alexopoulos EC. Adherence to Treatment in Stroke Patients. Int J Environ Res Public Health 2019; 16: 196.

28. Kaddumukasa M, Kayima J, Kaddumukasa MN, Ddumba E, Mugenyi L, Pun-dik S, et al. Knowledge, attitudes and perceptions of stroke: a cross-sectional survey in rural and urban Uganda. BMC Res Notes 2015; 8: 819.

29. Basfar W, Al-Sebyani A, Aljawi G, Milyani H, Jan M. Public Knowledge of Stroke Amongst a Saudi Population. World Journal of Research and Review 2016; 3: 10-12.

30. Aljefree N, Ahmed F. Prevalence of cardiovascular disease and associated risk factors among adult population in the Gulf region: a systematic review. Ad-vances in Public Health 2015; 2015.

31. Luger S, Hohmann C, Niemann D, Kraft P, Gunreben I, Neumann-Haefelin T, et al. Adherence to oral anticoagulant therapy in secondary stroke prevention - impact of the novel oral anticoagulants. Patient Prefer Adherence 2015; 9: 1695-705. 
32. Tulek Z, Dünya C, Çiftçioğlu R, Dereci H. Determination of Factors that Im-pact Adherence to Warfarin in Patients with Stroke. Turkish Journal Of Neu-rology 2019; 25: 146-152.

33. Zhang H, Qian HZ, Meng SQ, Shu M, Gao YZ, Xu Y, et al. Psychological distress, social support and medication adherence in patients with ischemic stroke in the mainland of China. $J$ Huazhong Univ Sci Technolog Med Sci 2015; 35: 405-410.

34. Vincent-Onabajo G, Moses T. Knowledge of Stroke Risk Factors among Stroke Survivors in Nigeria. Stroke Res Treat 2016; 2016: 1902151.

35. Sundseth A, Faiz KW, Rønning OM, Thommessen B. Factors related to knowledge of stroke symptoms and risk factors in a norwegian stroke popula-tion. J Stroke Cerebrovasc Dis 2014; 23: 1849-1855.

36. Zeng Y, He GP, Yi GH, Huang YJ, Zhang QH, He LL. Knowledge of stroke warning signs and risk factors among patients with previous stroke or TIA in China. J Clin Nurs 2012; 21: 2886-2895.

37. Senior V, Marteau TM, Weinman J, Genetic Risk Assessment for FHTSG. Self-reported adherence to cholesterol-lowering medication in patients with familial hypercholesterolaemia: the role of illness perceptions. Cardiovasc Drugs Ther 2004; 18 : 475-481.

38. Jin J, Sklar GE, Min Sen Oh V, Chuen Li S. Factors affecting therapeutic compliance: A review from the patient's perspective. Ther Clin Risk Manag 2008; 4: 269-286.

39. O'Carroll R, Whittaker J, Hamilton B, Johnston M, Sudlow C, Dennis M. Predictors of adherence to secondary preventive medication in stroke patients. Ann Behav Med 2011; 41: 383-390.
40. Glader EL, Sjölander M, Eriksson M, Lundberg M. Persistent use of second-ary preventive drugs declines rapidly during the first 2 years after stroke. Stroke 2010; 41: 397-401.

41. Jamison J, Sutton S, Mant J, De Simoni A. Barriers and facilitators to adher-ence to secondary stroke prevention medications after stroke: analysis of sur-vivors and caregivers views from an online stroke forum. BMJ Open 2017; 7: e016814-e.

42. Chambers JA, O'Carroll RE, Hamilton B, Whittaker J, Johnston M, Sudlow C, et al. Adherence to medication in stroke survivors: a qualitative comparison of low and high adherers. $\mathrm{Br}$ J Health Psychol 2011; 16: 592-609.

43. Al AlShaikh S, Quinn T, Dunn W, Walters M, Dawson J. Predictive factors of non-adherence to secondary preventative medication after stroke or transient ischaemic attack: A systematic review and meta-analyses. Eur Stroke J 2016; 1: 65-75.

44. Lummis HL, Sketris IS, Gubitz GJ, Joffres MR, Flowerdew GJ. Medication persistence rates and factors associated with persistence in patients following stroke: a cohort study. BMC Neurol 2008; 8: 25.

45. Østergaard K, Madsen C, Liu ML, Bak S, Hallas J, Gaist D. Long-term use of antiplatelet drugs by patients with transient ischaemic attack. Eur J Clin Pharmacol 2014; 70: 241-248.

46. Ovbiagele B, Saver JL, Fredieu A, Suzuki S, Selco S, Rajajee $\mathrm{V}$, et al. In-hospital initiation of secondary stroke prevention therapies yields high rates of adherence at follow-up. Stroke 2004; 35: 2879-83.

\section{Supplements}

* Supplements will be considered for work including proceedings of conferences or subject matter covering an important topic

* Material can be in the form of original work or abstracts.

* Material in supplements will be for the purpose of teaching rather than research.

* The Guest Editor will ensure that the financial cost of production of the supplement is covered.

* Supplements will be distributed with the regular issue of the journal but further copies can be ordered upon request.

* Material will be made available on Saudi Medical Journal website 